\title{
Evaluation of Root Canal Morphology and Anatomy of Maxillary Second Premolars Using Cone-Beam Computed Tomography
}

\author{
Maryam Tofangchiha ${ }^{1}$, Marjan Bolbolian ${ }^{2}$, Amin Ghasemi ${ }^{3}$, Nahid Hemmati ${ }^{4}$ \\ 1.Associate Professor, Department of Oral and Maxillofacial Radiology, Dental Caries Prevention Research Center, Qazvin \\ University of Medical Sciences, Qazvin, Iran. ORCID ID: 0000-0002-5515-2189 \\ 2.Assistant Professor, Department of Endodontics, Dental Caries Prevention Research Center, Qazvin University of Medical \\ Sciences, Qazvin, Iran, (Corresponding Author), Tel: +98-28-33353064, Email: marjan.bolbolian@yahoo.com. ORCID ID: \\ 0000-0002-9064-5122 \\ 3.General Dentist, Student Research Committee, Qazvin University of Medical Sciences, Qazvin, Iran. ORCID ID: 0000- \\ 0003-1500-3928 \\ 4.Post-graduate Student, Department of Prosthodontics, Student Research Committee, Qazvin University of Medical \\ Sciences, Qazvin, Iran. ORCID ID: 0000-0002-2638-6154
}

\begin{abstract}
Background and Aim: Evaluation of root and canal morphology and anatomy of the teeth is essential for successful root treatment. This study aimed to evaluate the morphology and anatomy of the root canal of maxillary second premolars using the cone-beam computed tomography $(\mathrm{CBCT})$ technique in a radiology center.

Material and Methods: We used CBCT images of a specialized radiology center archived in 2014 in Qazvin and evaluated them by use of Remexis software. Evaluation of the images was carried out by a radiologist and an endodontist. The number of roots and their morphology, number of canals, the direction of root curvature, and canals in buccolingual and mesiodistal directions were assessed using the chi-square test in two genders. The significance level was considered 5\%.
\end{abstract}

Results: A total number of 106 CBCT involving 117-second premolar teeth were evaluated. $93.2 \%$ of the teeth had one root and $6.8 \%$ had two roots. There was no significant difference in the number of roots between the two sexes $(\mathrm{Pv}=0.164)$. According to Vertucci classification for single- rooted teeth, $59.6 \%$ were of type I, $20.2 \%$ of type II, $9.2 \%$ of type III, $0.9 \%$ of type IV, $6.4 \%$ of type V, $1.8 \%$ of type VI, and $1.8 \%$ of type VII. Among two rooted second premolar teeth, $87.5 \%$ were of type I and $12.5 \%$ of type III.

Conclusion: In maxillary second premolars, the majority of teeth had one root with type I and type II canals. During root treatment, these anatomical variations should be considered.

Keywords: Anatomy, Tooth root, Premolar, Morphology, Root canal

Received: Aug 27, $2019 \quad$ Accepted: Feb 5, 2019

How to cite the article: Maryam Tofangchiha, Marjan Bolbolian, Amin Ghasemi, Nahid Hemmati. Evaluation of Root Canal Morphology and Anatomy of Maxillary Second Premolars Using Cone Beam Computed Tomography .ŚSKU 2020;25(5):84-92.

Copyright (C) 2018 the Author (s). Published by Kurdistan University of Medical Sciences. This is an open access article distributed under the terms of the Creative Commons Attribution-Non Commercial License 4.0 (CCBYNC), where it is permissible to download, share, remix, transform, and buildup the work provided it is properly cited. The work cannot be used commercially without permission from the journal 


\title{
بررسى آناتومى ومورفولوزى ريشه و كانال يره مولر دوم فك بالا با استفاده از توموكر افى كامييوترى برتو مخروطى
}

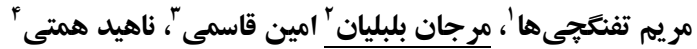

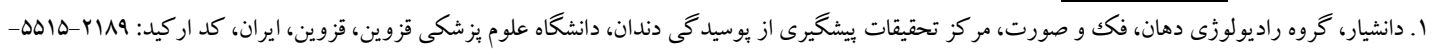

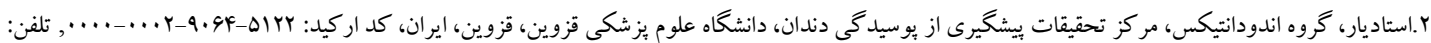 \\ E-mail: marjan.bolbolian@yahoo.com ،.rA-rrror.q4

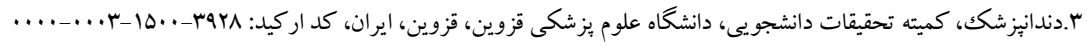

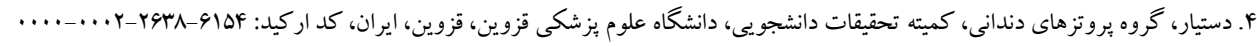

جְكيده

مقدمه و هدف: بررسى مورفولوزى و آناتومى ريشه و كانال دندان ها جهت موفقيت درمان ريشه اهميت زيادى دارد. هدف از

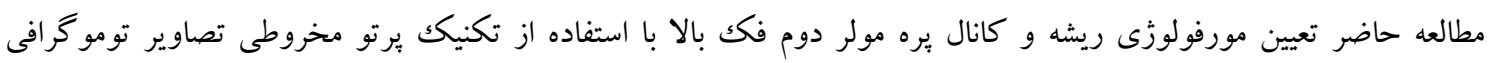

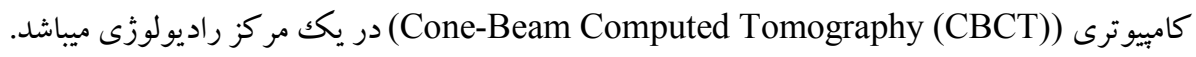

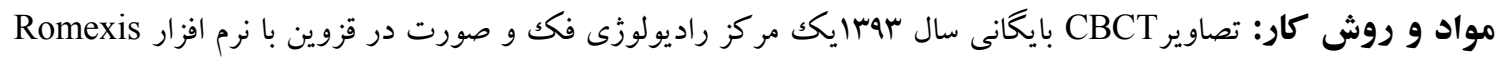

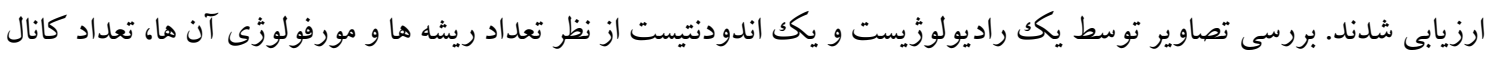

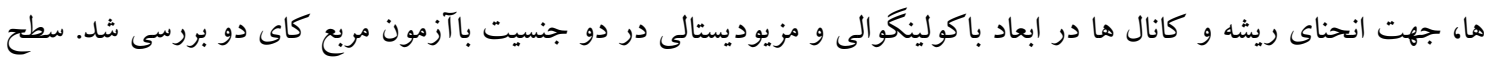

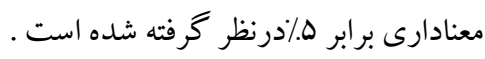

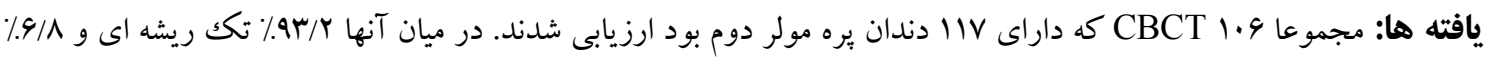

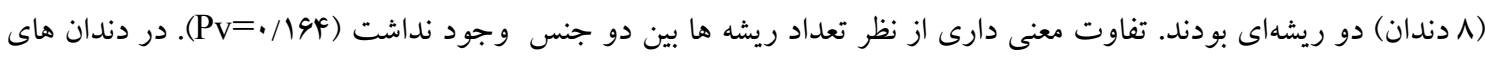

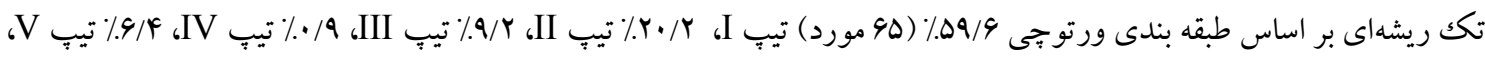

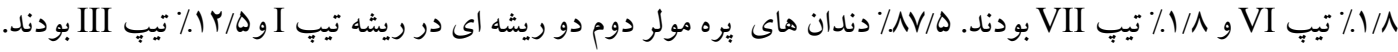

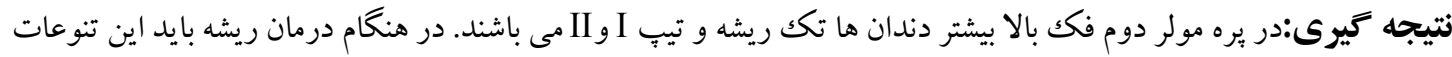

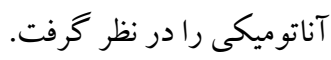

وازگان كليدى: آناتومى، ريشه دندان، يره مولر، مورفولوزى، كانال دندان

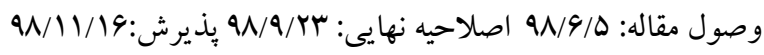


بيجيدگى سيستم كانال ريشه را مشاهده كرده و م نوع طبقه

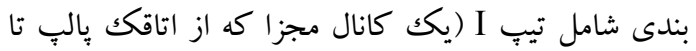
إيكس امتداديافته)، تيب II (دو كانال مجزا كه از اتاقك پِالب جداشده و در نزديكى إِكس به هم متصل و يكك

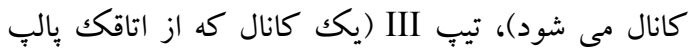
جدا شده و در ريشه به دو كانال تقسيم مى شود و سبس اين دو كانال يكى شده و يكك كانال را شكل مى دهد و تا إِكس ادامه مى يابد.)، تيب IV (دو كانال مجزا كه از

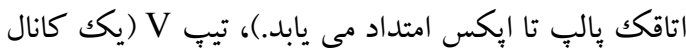

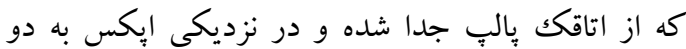

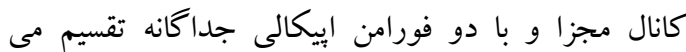

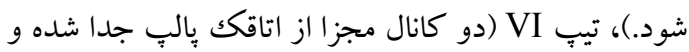
در طول ريشه با هم يكى شده و در نزديكى إِكس مجدداً

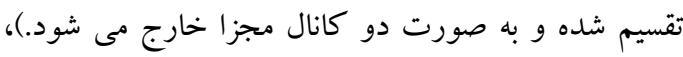

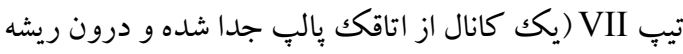

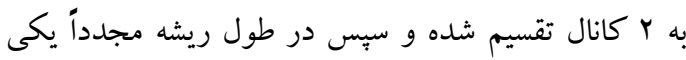
شده و در نهايت در نزديكى إِكس به صورت دو دو كانال

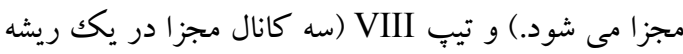

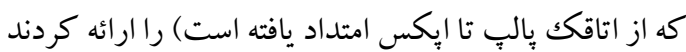

(تصوير (). (ت)

روش هاى متعددى جهت بررسى آناتومى و مورفولوزى النى

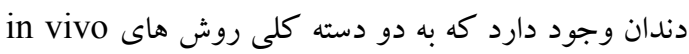

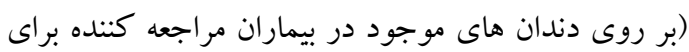
درمان) و ex vivo (بر روى دندان هاى كشيده شده در

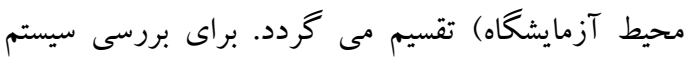
كانال ريشه روش هاى مختلف نسبتا قديمى مانند راديو گر افى ورنگك آميزى و نيز مدرن مانند سى تى دهى اسكن، ميكرو سى تى اسكن و برتو مخروطى تصاوير تومو گرافى ونى كامييوترى Cone-Beam Computed Tomography) ) وجود دارد كه سبب افزايش درك دندانيزشك (CBCT)

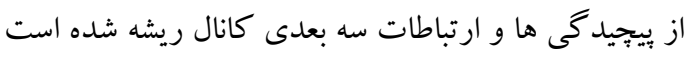

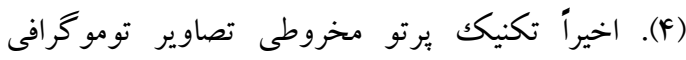

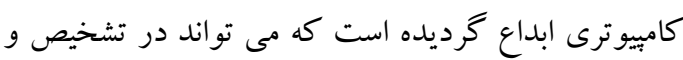

مقدمه

بافت سختى كه دندان را احاطه كرده است مى تواند شكل و ساختارى متنوع به خود بحيرد و دندانيزشك بايد دركى از

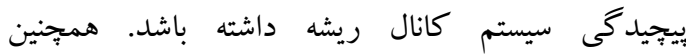
دندانيز شك بايد اصول و مشكلات شكل دهى و بِاكسازى را دركك كند تا بتواند حدود إيكالى و ابعاد آماده سازى را تعيين كرده و درمان مطلوبى را انجام دهد. گزارشات از آناتومى هاى ييجيده در حال افزايش است و اين مسئله نشان مى دهد كه اخر فرد از قبل منتظر ديدن يك آناتومى خاص باشد راحت تر آن را تشخيص مى دهد (1). بنابراين ييش از اقدام به درمان ريشه كسب آكاهى كافى از ساختمان كانال

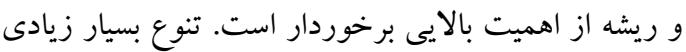
درتعداد و شكل كانال ها در هر ريشه و تعداد ريشه ها براى له دندان هاى يره مولر فك بالا گزارش شده است (r، r). دندانيز شكان از تمامى امكانات موجود و در دسترس براى برى يافتن و درمان نمودن سيستم كانال ريشه استفاده مى نمايند زيرا كانال درمان نشده مى تواند يكى از مهمترين دلايل

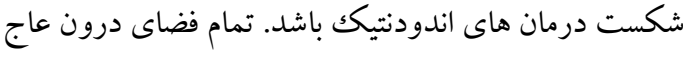

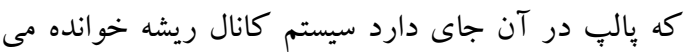

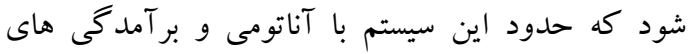
خارجى دندان مطابقت دارد. يُره مولر دوم فكك بالامى تو اند

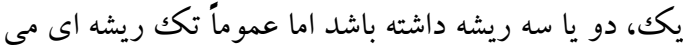
باشد (V/9\%). هرجند درصورت بروز تقارن دوطرفه، وجود

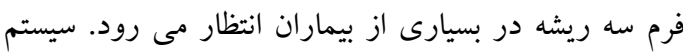
كانال ريشه يره مولر دوم فك بالا از نظر باكولينكول عريضتر از مزيوديستالى است. ريشه كانال ممكن است در يكك ريشه منفرد وجود داشته باشد (1). تاكنون طبقه بندى هاى متعددى مانند طبقه بندى وينه با ها تيب مختلف (ه)، ورتوجى و همكاران با 1 تيب مختلف (9) و كلابيوالا و

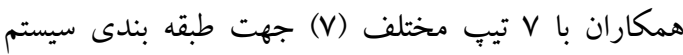
كانال ريشه و تنوعات آناتوميكى آن ارائه شده است. ورتوجى و همكاران با استفاده از دندانهائى كه شفاف شده و سبس توسط هماتو كسيلين رنگك آميزى شده اندها 
بررسى ميزان تشابه نوع واريانت در يرى مولرهاى دوم قرينه

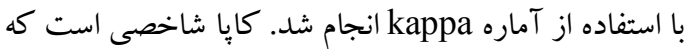

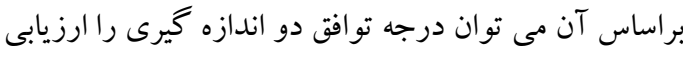
نمود. ضريب توافق كايا بيش از •^^/ يكسانى (توافق بالا)،

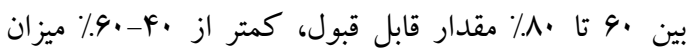

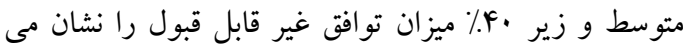

دهد.

يافته ها

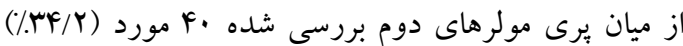

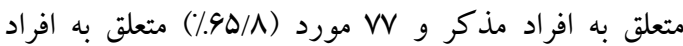

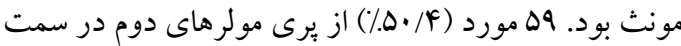

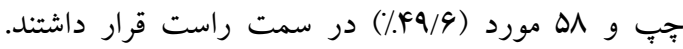
همجنين سا جفت دندان بِره مولر دوم قرينه (1 جفت مردو ها جفت زن) قابل بررسى بود. تعداد ريشه ها و شكل كانال ها به تفكيكك جنسيت و به صورت كلى در جدول آ آورده شده است. همانطورى كه در جدول آ آورده شده است، از IIV دندان يره مولر دوم فكك بالا بررسى شده، 1 إدندان

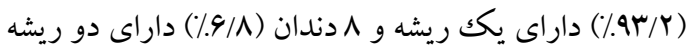
بودند. در آقايان از دندان هاى بره مولر دوم فكك بالا بررسى شده، وץ دندان تكك ريشه اى و F دندان دو ريشه اى بود. اما

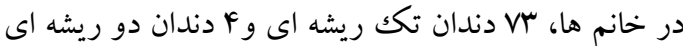
وجود داشت. تفاوت معنى دارى از نظر تعداد ريشه ها در دندان بره مولر دوم بين خانم ها و آقايان وجود نداشت (Pv=./194) (مانطور كه در جدول r نشان داده شده

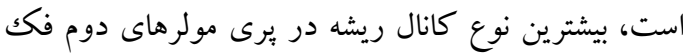
بالا تكك ريشه براساس طبقه بندى ورتوجى درخانم ها و

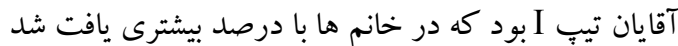
بود كه در آقايان با

$$
\text { درصد بيشترى يافت شد. }
$$

ارزيابى مورفولوزى كانال و ريشه مفيد باشد و در هر دو

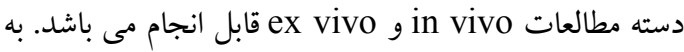
كمك اين روش مى توان از CBCT هاى بيماران براى

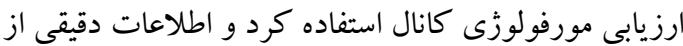
آناتومى و مورفولوزى ريشه و كانال ها بدست آورد (م). از طرفى يكك سوم إيكالى ريشه دندان ناحيه اى مهم از نظر تعيين طول كاركرد و ارتباط با بافت زنده وييرامون است، بنابراين بطور مستقيم بر ترميم ضايعات يرى إيكال

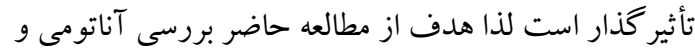

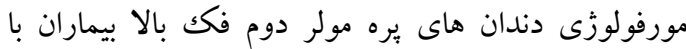
استفاده از تصاوير تهيه شده با CBCT مى باشد.

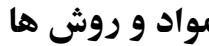

در اين مطالعه مقطعى توصيفى، با مراجعه به بايشانى يك كلينيك راديولوزى در شهر قزوين در سالسهبا، تصاوير موجود كه حاوى دندان هاى فاقد ضايعات يرى CBCT إيكال و درمان ريشه، بدون بر كردگى وسيع تاج كانال ريشه و نبودن تاج بود استفاده گرديد. همجنين معيار ورود به مطالعه كيفيت بالاى عكس هاى CBCT در

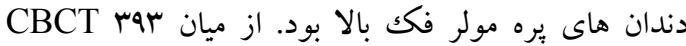
موجود، تنها 1.9 عدد شرايط فوق الذكر جهت ورود به مطالعه را داشتند. تصاوير مورد نظر با نرم افزار كامييوترى Romexis با ميزان نور و روشنايى تنظيم شده جهت ايجاد تصوير مطلوب با بيشترين شفافيت توسط يك راديولوزيست و يكك اندودنتيست به صورت هم زمان مورد ارزيابى قرار كرفت. متغيير مورد ارزيابى شامل تعداد ريشه ها و و مورفولوزى آن ها، تعداد كانال ها در ريشه ها، جهت

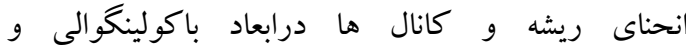
مزيوديستالى، به همراه مشخصات دمو گرا افيك بيماران بود. اطلاعات مربوطه با استفاده از نرم افزار آمارى SPSS نسخه سب و توسط آزمون هاى آمارى مربع كاى آناليز گرديد. 
جدول ا: فراوانى (درصد) تعداد ريشه و شكل كانال در يرى مولرهاى دوم فك بالا

\begin{tabular}{|c|c|c|c|c|c|c|c|c|c|}
\hline كل & \multicolumn{3}{|c|}{ دوريشه با سه كانال } & \multicolumn{3}{|c|}{ يكك ريشه با دو كانال } & \multicolumn{2}{|c|}{ يك ريشه با يكك كانال } & جنسيت \\
\hline f. & \multicolumn{2}{|c|}{$(1 \cdot / \cdot)^{4}$} & & \multicolumn{2}{|c|}{$(F V / 0) 19$} & & \multicolumn{2}{|c|}{$(F Y / D) I V$} & مذكر \\
\hline VV & \multicolumn{2}{|r|}{$(\Delta / Y) F$} & & \multicolumn{2}{|c|}{ (KM/N) YG } & & \multicolumn{2}{|c|}{$(91 / \cdot) \mathrm{FV}$} & مونث \\
\hline $11 \mathrm{~V}$ & \multicolumn{2}{|r|}{$(9 / \Lambda) \wedge$} & & \multicolumn{2}{|c|}{$(r \wedge / \Delta) F \Delta$} & & \multicolumn{2}{|c|}{$(\Delta F / V) G F$} & كل \\
\hline \multicolumn{10}{|c|}{ جدول r: فراوانى (درصد) مورفولوزى دندان هاى يره مولر دوم فك بالا براساس طبقه بندى ورتوجى } \\
\hline \multirow[t]{2}{*}{ كل } & تيب VII & تيب VI & Vيب V V & تيب IV & تيب III & تيب II & تيب I & جنسيت & تعداد ريشه \\
\hline & & & & & & & & & تكك ريشه اى \\
\hline rq & $(Y / \Lambda) 1$ & $(\Delta / 9) r$ & $(Y / \Lambda))$ & . & $(Y / \Lambda) 1$ & $(F \mid / V) 10$ & $(F F / F) 1 q$ & مذكر & \\
\hline vr & $(1 / \mathcal{f}) 1$ & . & $(\Lambda / Y) 9$ & $(1 / 4) 1$ & $(\mid r / r) q$ & $(9 / 9) \vee$ & $(q \mathrm{~V} / 1)<q$ & 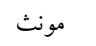 & \\
\hline \multirow[t]{3}{*}{1.9} & $(1 / \Lambda) r$ & $(1 / A) r$ & $(g / F) V$ & $(\cdot / 9) 1$ & $(9 / r))$ & $(r \cdot / r) r r$ & $(\Delta 9 / 9) 90$ & كل & \\
\hline & & & & & & & & & دو ريشه اى \\
\hline & & & & & & & & & كانال باكال \\
\hline f & - & - & - & - & . & - & $(1 .) r$. & مذكر & \\
\hline f & - & - & - & - & $(r \Delta / \cdot))$ & - & $(V \Delta / \cdot) r$ & 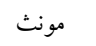 & \\
\hline \multirow[t]{2}{*}{$\wedge$} & - & - & - & - & $(T \Delta \mid r) 1$ & - & $(\Lambda V / \Delta) V$ & كل & \\
\hline & & & & & & & & & كانال بِالاتال \\
\hline f & - & - & - & - & . & - & $(1 \cdots)^{f}$ & مذكر & \\
\hline f & - & - & - & - & . & - & $(1 .) r$. & مونث & \\
\hline$\wedge$ & - & - & - & - & . & - & $(1 \cdots) \wedge$ & كل & \\
\hline
\end{tabular}

جدول rا: فراوانى (درصد) دندان ها به تفكيكى جنسيت بر اساس ارزيابى انحناى يك سوم اييكال ريشه در دندان بره مولر دوم فك

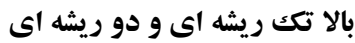

\begin{tabular}{|c|c|c|c|c|c|c|}
\hline 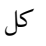 & زن ان & مرد ل & انحناى ريشه & ريشه & جهات انحناى ريشه & تعداد ريشه \\
\hline rq & $(F q / r) \mid r$ & $(\Delta r / \Lambda) \backslash F$ & باكال & & بو كولينكوال & تكك ريشه اى \\
\hline$\wedge$ & $(9 Y / \Delta) \Delta$ & $(r V / \Delta) r$ & لينكوال & & & \\
\hline vo & $(V \& / V) \Delta G$ & $(r \Delta / r) 19$ & مستقيم & & & \\
\hline 11 & $(91 / 1) 11$ & $($ ( N/q) V & 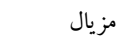 & & مزيوديستال & \\
\hline fr & $(V G / Y) r Y$ & $(\Gamma \Gamma / \Lambda) 1$. & ديستال & & & \\
\hline Fq & $(q 1 / r) r$. & $($ (rN/A) 19 & مستقيم & & & \\
\hline 1 & $(1 . . \cdot) 1$ & $\cdot$ & باكال & باكال & بو كولينگ ال & دو ريشه اى \\
\hline r & · & $(1 \cdot \cdot) r$ & 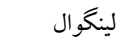 & & & \\
\hline$\Delta$ & $(9 \cdot / \cdot) \mu$ & $(k \cdot / \cdot) r$ & مستقيم & & & \\
\hline 1 & $(1, \cdot) 1$ & $\cdot$ & باكال & 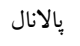 & & \\
\hline r & - & $(1 \cdot \cdot) r$ & ل لينگو ال & & & \\
\hline$\Delta$ & $(9 \cdot / \cdot) r$ & $(F \cdot / \cdot) r$ & مستقيم & & & \\
\hline 1 & $(1 .) 1$. & . & 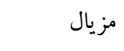 & باكال & مزيوديستال & \\
\hline r & $(1 \cdots) r$ & $\cdot$ & ديستال & & & \\
\hline$\Delta$ & $(r \cdot / \cdot))$ & $(\Lambda \cdot / \cdot) F$ & مستقيم & & & \\
\hline 1 & $(1, \cdot) 1$ & $\cdot$ & 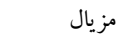 & 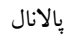 & & \\
\hline 1 & $(1 \cdots) 1$ & $\cdot$ & ديستال & & & \\
\hline 4 & $(r r / r) r$ & $(99 / \mathrm{V}) \mathrm{F}$ & مستقيم & & & \\
\hline
\end{tabular}

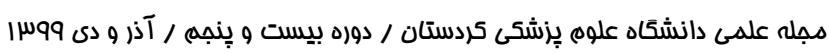




$$
\begin{aligned}
& \text { جدول ^† فراوانى (درصد) دندان ها به تفكيك جنسيت بر اساس ارزيابى انحناى يكك سوم اييكال كانال در دندان بره مولر اول }
\end{aligned}
$$

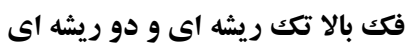

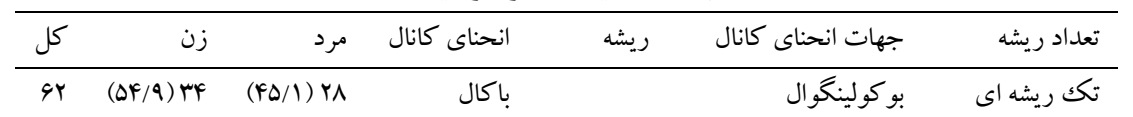

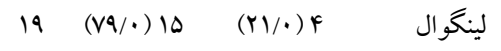

$$
\begin{aligned}
& \text { مستقيم } \\
& \text { مزيوديستال } \\
& \text { د د } \\
& \text { FV } \\
& \text { دو ريشه ائ }
\end{aligned}
$$

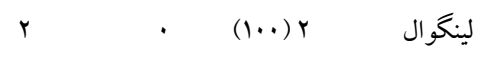

$$
\begin{aligned}
& \text { مستقيم } \\
& \text { r بالاتال } \\
& \text {. . . . ل ل }
\end{aligned}
$$

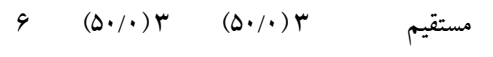

$$
\begin{aligned}
& \text { مزيوديستال } \\
& \text { r } \\
& \text { r مستقيم }
\end{aligned}
$$

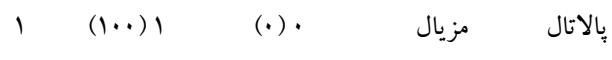

$$
\begin{aligned}
& \text { S د }
\end{aligned}
$$

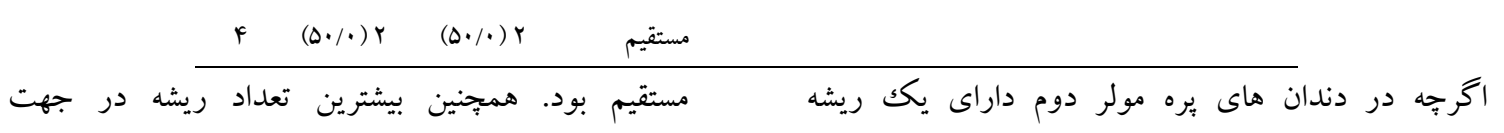

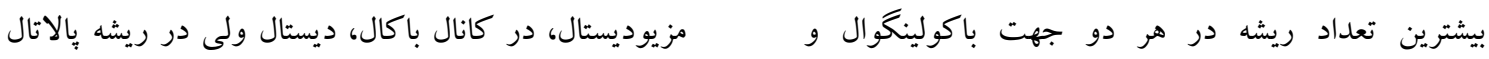

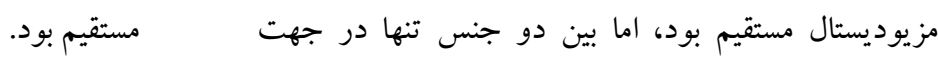

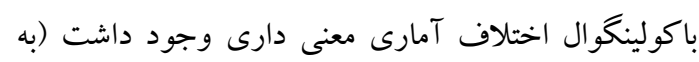

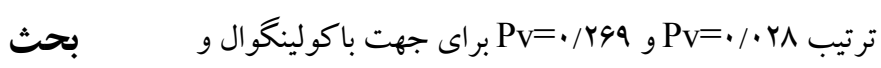

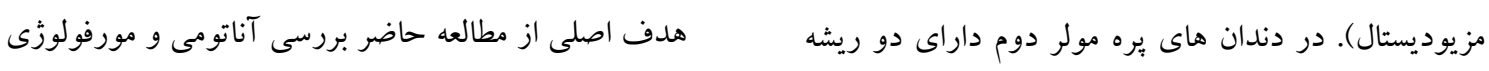

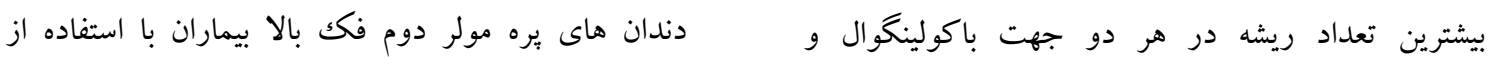

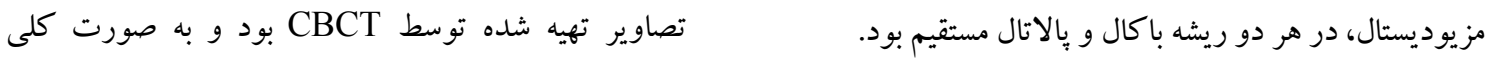

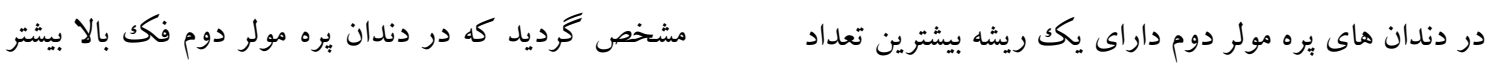

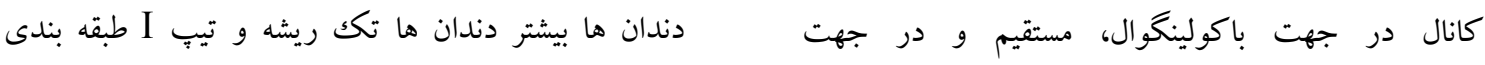

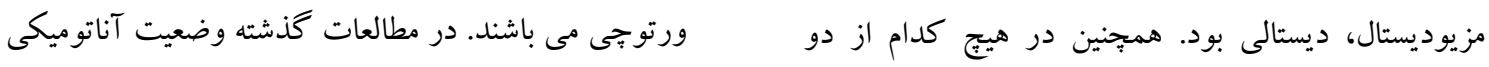

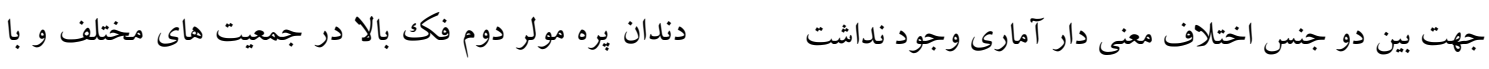

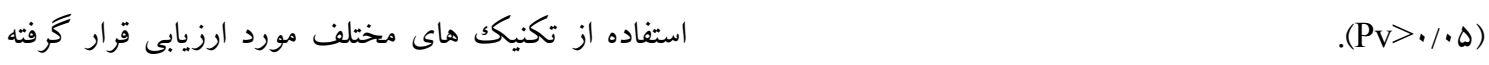

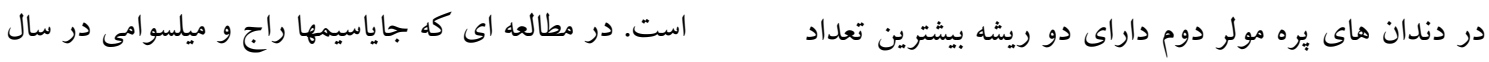

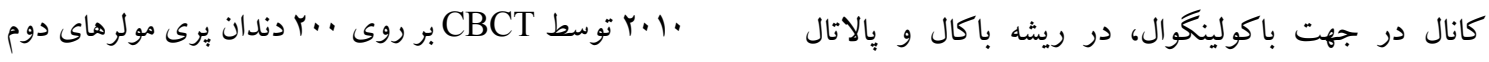


كرفته احتمال ديده نشدن كانال و تغيير در طبقه بندى وجود داشته است. با توجه به وجود گوتا ير كا در كانال به عنوان ماده راديوإيك و ايجاد اشعه يِ اكنده، بررسى دقيق كانال را دشوار مى نموده است. در مطالعه اى كه اكى و همكاران در

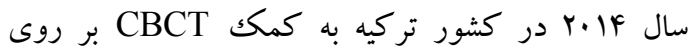
مورفولوزى كانال يرى مولرهاى فك بالا و منديبل انجام شد، مشخص كرديد كه شايع ترين تعداد و نوع كانال براى

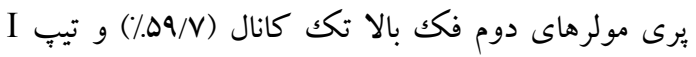

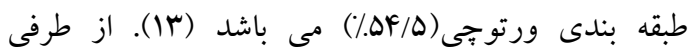
مشاهده نمودند كه شيوع دندان هاى تكك كاناله در زنان بيشتر مى باشد و شيوع دندان هاى دو و سه كاناله در مردان بيشتر مى باشد. همجنين در مطالعه آنان يرى مولرهاى تك كاناله بيشتر در سمت جٍِ و دو كاناله بيشتر در سمت راست مشاهده شد (سا). هر جֶند در مطالعه حاضر نيز اين تفاوت هاى جنسيتى ديده شد اما اين تفاوت از نظر آمارى معنى دار نبود. يرتوى و مظفرى در سال ه • •r در يكك بررسى تجربى تعداد

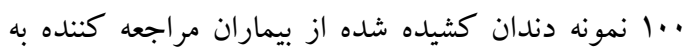
مراكز درمانى را به كمكك تزريق جوهر هندى رنگك اميزى كرده و تعداد ريشه ها و انواع مختلف كانال ها و محل آييكال فورامن بر اساس تقسيم بندى ورتوجى بررسى كردند. آن ها بيان كردند كه بيشترين فراوانى مربوط به دندان هاى تكك ريشه اى تيب II ورتو تِى مى باشد (IF).

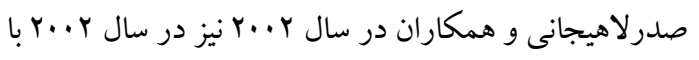
بررسى •هس دندان يِش فك يايين و دندان هاى يرى مولار

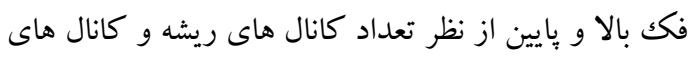

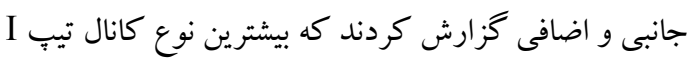
ورتوجى مى باشد (ه) (1ه). شاهى و شريف زاده در سال

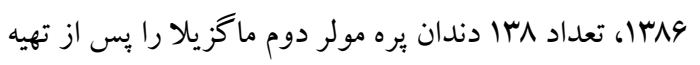
حفره دسترسى، به وسيله اسيد نيتريك هـ/ د كلسيفيه كرده و بعد از دهيدراتاسيون با استفاده از متيل ساليسيلات شفاف و بعد از تزريق رنگك آميزى و مورد بررسى قرار دادند. نتايج نشان داد كه دندان هاى بره مولر دوم ماكزيلا •هـ/ يكك
فكك بالا انجام دادند نشان داد كه / \% / از دندان ها داراى يكك كانال و \&/هr/ از دندان ها داراى دو كانال در إيكس بودند . ميانكين طول ريشه دندانها ه// r ميلى متر بوده و

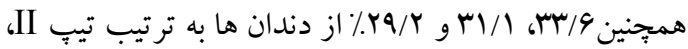
و IV IV ناصرى و همكاران در كشور ايران در سال الهسا در بررسى تجربى آزمايشگاهى •ه عدد دندان بره مولر دوم فك بالا كشيده شده از بيماران مراجعه كننده به مراكز درمانى شهر تهران نشان داد كه در دندان هاى تكك كاناله يره مولر دوم ماگزيلا بيشترين انحراف اييكال فورامن از إيكس آناتوميك تهر بيشتر در جهت مزيولينگوال و در دندانهاى دو كاناله دركانال باكال بيشترين انحراف در جهت مزيوباكال و مزيولينگوال و در كانال يالاتال در جهت ديستولينگوال بوده است. همجِين آن ها بيان كردند كه شايع ترين انواع كانال I بر طبق طبقه بندى ورتوجى در دومين يره مولر تيب

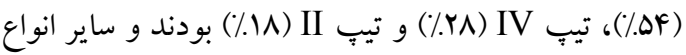
كانالها در دندان هاى مورد مطالعه آن ها مشاهده نشد ( •(1). ساعد النزهان و همكاران در كشور عربستان در r Y r به به كمكك راديوكرافى بر روى اسم دندان بره مولر دوم فك بالا كه درمان ريشه شده بودند را بررسى كرده و مشاهده كردند كه بيشتر از •هـ\% از دندان هاى بره مولر دوم فكك بالا دو كاناله بودند و باقى موارد تكك كاناله بودند. همبجنين در اين مطالعه هيج رابطه ایى مبنى بر تاثير فاكتور جنسيت در شيوع دو كاناله بودن دندان ها مشاهده نشد (11). در مطالعه مونا و همكاران نشان داده شد كه از ميان MIV دندان يره

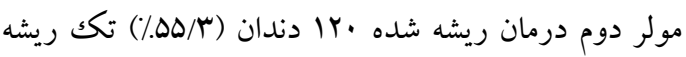
اى، 94 دندان دو ريشه اى (YF/YF/) و فقط يك دندان (ه/•(٪) سه ريشه اى يافت شد. با توجه به طبقه بندى

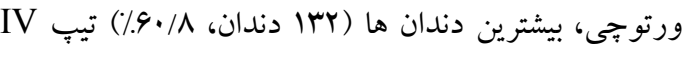
بودند (r). اختلافات مو جود در اين مطالعه با مطالعه حاضر را مى توان ناشى از تعداد نمونه، جمعيت مورد مطالعه و تفاوت در نزادها دانست. به علاوه با توجه به اينكه مطالعه ذكر شده بر روى دندان هاى درمان ريشه شده صورت 


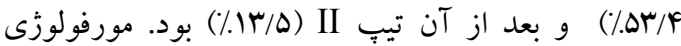

كانال ريشه دندان ها تفاوتى در خانم ها و آقايان نداشت

نتايج اين مطالعه به نتايج مطالعه صدرلاهيجانى و همكاران

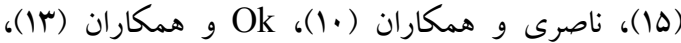

القادرى و همكاران (1) و Nazeer و همكاران (19) نزديك تر بوده اما با مطالعه يُرتوى و همكاران (If)، (9) Mylswamy gayasimha Raj همكاران (II)، مونا و همكاران (rا) و Celikten و همكاران (IV) اندكى متفاوت است. علت تفاوت در نتايج مطالعات را مى توان تفاوت در جمعيت و منطقه جغرافيايى مورد مطالعه، فراوانى جنسيتى جمعيت ها و نيز روش هاى ارزيابى كانال و ريشه دانست.

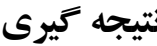

به صورت كلى مى توان بيان كرد كه بر طبق يافته هاى

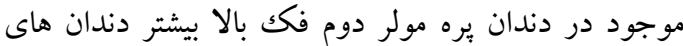
تكك ريشه تيب I طبقه بندى ورتوجى مى باشند. همجنين

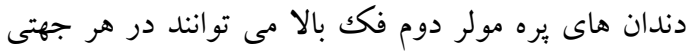
داراى انحنا باشند. در مجموع اين مطالعه نشان مى دهد كه به راديو گرافى CBCT در كشف آناتومى دندان ها كمكك كننده است. با توجه به احتمال وجود كانال هاى اضافى بررسى دقيق حفره دسترسى جهت مشخص كردن وجود به به كانال دوم يا سوم، حين درمان كانال ريشه توصيه مى شود.

\section{تشكر و قدردانى}

بدين وسيله از دانشكده دندانيزشكى، دانشگاه علوم يزشكى قزوين، جهت همكارى با نويسندكان تقدير و تشكر مى بـ كردد.

كاناله و •هـ٪ دو كاناله هستند. آن ها نتيجه گيرى كردند كه دندان هاى بره مولر دوم ما گزيلا را هميشه بايد دو كاناله در نظر گرفت مخر اينكه خلاف آن ثابت شود (19).

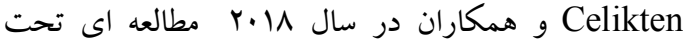
عنوان بررسى مورفولوزى كانال ريشه دندان هاى بره مولر ماززيلا و منديبل به كمك CBCT در جمعيت هاى تركى قبرس انجام دادند. بر اساس نتايج اين مطالعه در دندان هاى

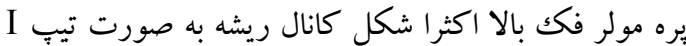
و تيب IV ورتوجى بود. در اين مطالعه، فاكتور هاى جنسيت و سمت راست و جֶٍ تفاوتى در نتيجه مطالعه ايجاد نكرده

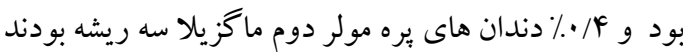

القادرى و همكاران در سال 1 إr مورفولوزى كانال ريشه دندان هاى يره مولر ماكزيلا رادر جمعيت سعودى به كمك هـ بررسى كردند. بر اساس نتايج اين مطالعه دندان

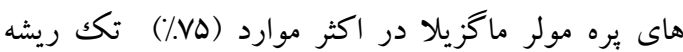

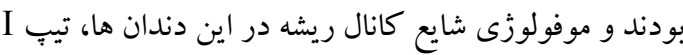

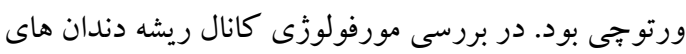

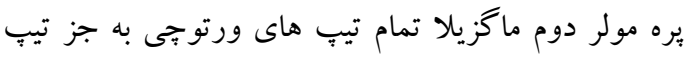
يافت شد. در اين مطالعه جنسيت ارتباط مشخصى با

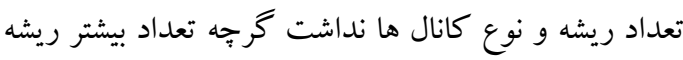
در مرد ها يافت شد (1N) - (1).

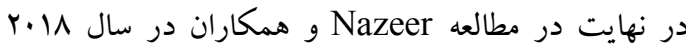
مورفولوزى ريشه و كانال دندان هاى بره مولرهاى ماكزيلا به كمك CBCT در جمعيت پٍاكستانى بررسى شد. در اين

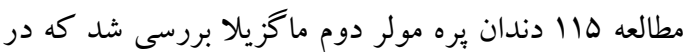

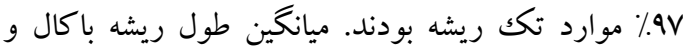

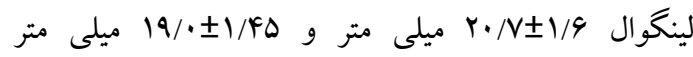

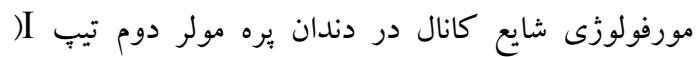

منابع 1.Hargreaves KM, Cohen S. Cohen's Pathways of the Pulp. $10^{\text {th }}$ ed. St. Louis, Missouri; Mosby: 2011. Pp.136-221.

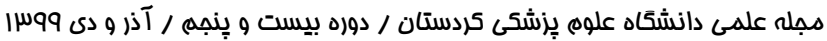


2.Ng YL, Aung TH, Alavi A, Gulabivala K. Root and canal morphology of Burmese maxillary molars. Int Endod J 2001; 34(8): 620-630.

3.Omer OE, Shalabi RM, Jennings M, Glennon J, Claffey NM. A comparison between clearing and radiographic technique in the study of root canal anatomy of maxillary molars. Int Endod J 2004; 37: 291-296.

4.Krasner P, Rankow HJ. Anatomy of the pulp-chamber floor. J Endod 2004; 30(1): 5-16.

5.Weine FS, Endodontic therapy. $5^{\text {th }}$ ed. St. Louis: Mosby; 1996. Pp. 242-243.

6 .Vertucci FJ. Root canal anatomy of the human permanent teeth. Oral Surg Oral Med Oral Pathol 1984; 58(5):589-599.

7.Gulabivala K, Opasanon A, Ng YL, Alavi A. Root and canal morphology of Thai mandibular molars. Int Endod J 2002; 35(1): 56-62.

8.Omer OE, Al Shalabi RM, Jennings M, Glennon J, Claffey NM. A comparison between clearing and radiographic techniques in the study of the root-canal anatomy of maxillary first and second molars. Int Endod J 2004; 37(5): 291-296.

9.Jayasimha Raj U, Mylswamy S. Root canal morphology of maxillary second premolars in an Indian population. J Conserv Dent 2010; 13(3): 148-151.

10.Nasseri M, Momayyez M, Ahangari Z. Topographic Evaluation of Apex and Root Canal of Maxillary Premolars in an Iranian Population. J Dent Sch 2013; 31(1): 8-14

11.Al-Nazhan S, Al-Daafas A, Al-Maflehi N. Radiographic investigation of in vivo endodontically treated maxillary premolars in a Saudi Arabian sub-population. Saudi Endod J $2012 ; 2(1): 1-5$.

12.Al-Ghananeem MMF, Haddadin K, Al-Khreisat AS, Al-Weshah M, Al-Habahbeh N. The Number of Roots and Canals in the Maxillary Second Premolars in a Group of Jordanian Population. International Journal of Dentistry 2014:76-79.

13.Ok E, Altunsoy M, Nur BG, Aglarci OS, Çolak M, Güngör E. A cone-beam computed tomography study of root canal morphology of maxillary and mandibular premolars in a Turkish population. Acta Odontol Scand 2014; 72(8): 701-706.

14.Sadr Lahijani M, Shariati M, Sadeghi M. Evaluation of root canal anatomy in mandibular anterior-teeth and mandibular and maxillary premolars in vitro. Journal of Rafsanjan University of Medical Science 2002; 1: 92-98.

15.Partovi, M, Mozzafari S. Root canal morphology of human maxillary second premolar. Journal of Babol University of Medical Sciences (JBUMS) 2005; 7(1): 34-36.

16.Shahi Sh, Sharifzadeh, R, Root Canal Configurations of the Maxillary First and Second Premolar Teeth (in vitro). Medical Journal of Tabriz University of Medical Sciences and Health Services 2007; 29 (1): 65-68.

17.Celikten B, Orhan K, Aksoy U, Tufenkci P, Kalender A, Basmaci F, et al. Cone-beam CT evaluation of root canal morphology of maxillary and mandibular premolars in a Turkish Cypriot population. BDJ Open 2016; 2: 15006.

18.Alqedairi A, Alfawaz H, Al-Dahman Y, Alnassar F, Al-Jebaly A, Alsubait S. Cone-Beam Computed Tomographic Evaluation of Root Canal Morfology of Maillary Premolarsin a Saudi Population. BioMed Research International 2018; 4: 1-8.

19.Nazeer MR, Khan FR, Ghafoor R. Evaluation of root morphology and canal configuration of Maxillary Premolars in a sample of Pakistani population by using Cone Beam Computed Tomography. J Pak Med Assoc 2018; 68(3): 423-427. 